\title{
Modelling shear-flexure interaction in equivalent frame models of slender reinforced concrete walls
}

\author{
P.E. Mergos and K. Beyer*,† \\ Earthquake Engineering and Structural Dynamics Laboratory (EESD), School of Architecture, Civil and Environmental \\ Engineering (ENAC), École Polytechnique Fédérale de Lausanne (EPFL), Laussane, Switzerland
}

\begin{abstract}
SUMMARY
Quasi-static cyclic tests on reinforced concrete (RC) walls have shown that shear deformations can constitute a significant ratio of the total deformations when the wall is loaded beyond the elastic regime. For slender RC walls that form a stable flexural mechanism, the ratio of shear to flexural deformations remains approximately constant over the entire range of imposed displacement ductilities. This paper proposes a method for incorporating shear-flexure interaction effects in equivalent frame models of slender $\mathrm{RC}$ walls by coupling the shear force-shear strain relationship to the curvature and axial strain in the member. The suggested methodology is incorporated in a finite element consisting of two interacting spread inelasticity sub-elements representing flexural and shear response, respectively. The element is implemented in the general finite element code IDARC and validated against experimental results of RC cantilever walls. In a second step, it is applied in inelastic static and dynamic analyses of tall wall and wall-frame systems. It is shown that ignoring shear-flexure interaction may lead to erroneous predictions in particular of local ductility and storey drift demands. Copyright $\odot 2013$ John Wiley \& Sons, Ltd.
\end{abstract}

Received 1 February 2013; Revised 21 June 2013; Accepted 1 August 2013

KEY WORDS: reinforced concrete; slender walls; shear-flexure interaction

\section{INTRODUCTION}

In regions of moderate to high seismicity, reinforced concrete (RC) walls are widely used as lateral stiffness and strength providing elements in medium to tall buildings. Because they are inherently stiff, they limit interstorey drifts and therefore prevent excessive damage to nonstructural components (Fardis, 2009). Furthermore, they offer adequate protection against collapse by preventing the development of soft-storey mechanisms. In accordance with capacity design principles, slender RC walls are designed to form a flexural mechanism when loaded beyond the elastic limit. None the less, because of the significant depth of the walls, shear deformations play an important role and therefore, when compared with RC frames, more sophisticated numerical models are required for predicting the seismic response of RC walls (Fardis, 2009).

The inelastic response of slender RC walls can be predicted well by finite element models, which combine shell elements with advanced analytical methodologies that account for the biaxial in-plane stress state in RC elements, such as the modified compression field theory (MCFT) by Vecchio and Collins (1986). Other advanced modelling techniques developed to analyze the response of slender $\mathrm{RC}$ walls are based on macroelements in which different elements are assigned a specific load-carrying mechanism, such as axial forces, bending moments and shear forces (Vulcano et al., 1988; Massone et al., 2006; Orakcal and Wallace (2006)).

\footnotetext{
*Correspondence to: Katrin Beyer, Earthquake Engineering and Structural Dynamics Laboratory, School of Architecture, Civil and Environmental Engineering, École Polytechnique Fédérale de Lausanne, Lausanne CH-1015, Switzerland †E-mail: katrin.beyer@epfl.ch
} 
In engineering practice, however, shear walls are often modelled using beam elements and several beam-column elements have been developed to model the inelastic response of RC members. The vast majority of these elements place emphasis on modelling the flexural response such as, for example, the force-based distributed inelasticity beam-column element with fibre cross-sections (Spacone et al., 1996). The variety of approaches for modelling the shear response when the wall responds in the inelastic regime is, however, rather limited.

In most structural engineering analysis programs that are used for equivalent frame analysis of RC wall systems, the shear stiffness of beam-column elements is assigned a constant value that cannot be updated during the analysis. This modelling approach has been supported by the misconception that the shear deformations will remain constant once the nominal yield force, which is determined by the flexural mechanism, is reached. As a result, the ratio of the modelled shear to flexural deformations decreases after the onset of flexural yielding. Experimental evidence, which goes back as far as the 1970s (Wang et al., 1975; Oesterle et al., 1976; Valenas et al., 1979) has, however, shown that this does not apply to real RC walls even if the walls are capacity designed. After flexural yielding, the shear deformations continue to increase because of interaction of shear and flexural deformations in the wall's plastic zone (Beyer et al., 2008; Beyer et al., 2011).

Various beam-column element models have been developed to capture shear-flexure interaction in RC members. The most sophisticated models are force-based or displacement-based fibre elements (e.g. Petrangeli et al., 1999; Guner and Vecchio, 2010), which use advanced analytical methodologies such as the disturbed stress field model (Vecchio et al., 2001) to capture the shear-flexure interaction. However, they necessitate the use of 2D constitutive material laws and require iterations at each fibre to obtain the section's strain field. Hence, the computational effort involved may hinder their applicability to response history analysis of large multi-storey structures.

Other beam-column elements with shear-flexure interaction apply appropriate modifications to phenomenological shear force $V$-shear strain $\gamma$ constitutive laws (e.g. Takayanagi et al., 1979) as a function of the corresponding section's flexural deformations in terms of curvatures or axial strains. This approach is computational efficient and leads typically to satisfactory results if the phenomenological $V-\gamma$ constitutive laws are used within their scope. Existing models of this category have been developed for modelling the response of RC beam and columns with structural deficiencies, which may fail in shear after yielding in flexure (e.g. Ricles et al., 1998; Marini and Spacone, 2006; Mergos and Kappos, 2012a). For these elements, shear deformations prior to shear failure play a minor role and shear resistance is the major issue of concern. Hence, they typically underestimate shear deformations of RC members expected to undergo significant ductility demands without failing in shear (Mergos, 2011).

The objective of this study is to suggest a constitutive $V-\gamma$ law for slender RC structural walls that accounts for shear-flexure interaction in such members. The suggested modifications are implemented in a beam-column element developed previously for the seismic analysis of RC structures with structural deficiencies (Mergos and Kappos, 2012a, 2012b). The resultant numerical model is first calibrated against experimental data of a slender RC wall. Then, it is employed for the inelastic analyses of tall RC wall and wall-frame structures. The results highlight the necessity of incorporating shearflexure interaction effects in the seismic analysis of such structures when not only the global response but also local ductility and drift demands are of interest.

\section{A SIMPLE ANALYTICAL MODEL FOR SHEAR-FLEXURE INTERACTION IN SLENDER RC WALLS}

Results from several series of quasi-static cyclic tests on slender, capacity-designed cantilever RC walls with different cross sections suggest that the ratio of shear to flexural displacement remains approximately constant over the entire range of applied displacement ductilities (Figure 1). A summary of experimental evidence supporting this hypothesis and a simple semi-empirical model for estimating the ratio of shear to flexural deformations is presented in Beyer et al. (2011). Based on this model a constitutive law for shear-flexure interaction in beam-column elements is developed.

Using the geometric relationships within Mohr's circle, the shear strain $\gamma$ of a cracked RC panel can be expressed as (Figure 2, Rabbat and Collins, 1978; Oesterle et al., 1984): 
a)

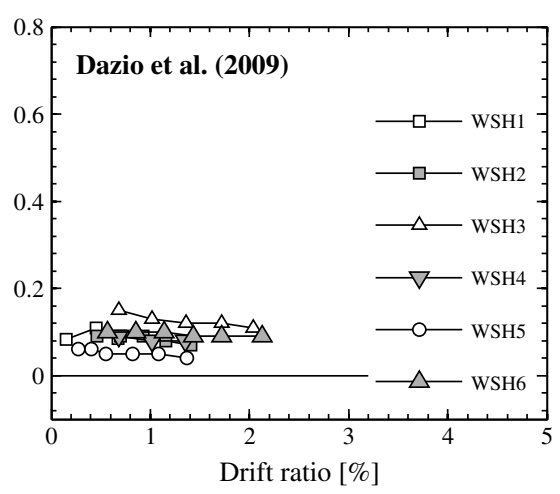

b)

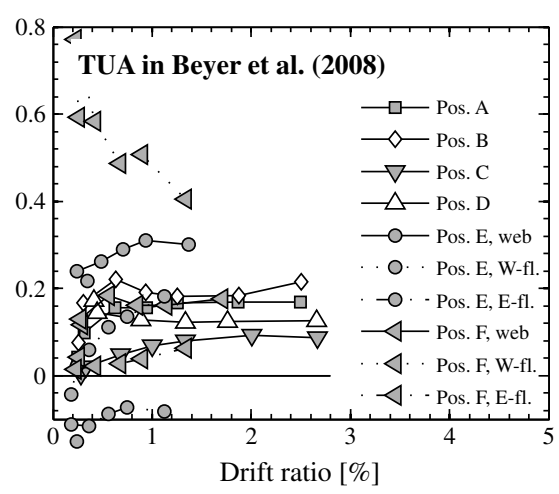

Figure 1. Variation of $\Delta_{\mathrm{s}} / \Delta_{\mathrm{f}}$ ratios with top drift for cantilever RC walls tested under quasi-static cyclic loading (Beyer et al., 2011).
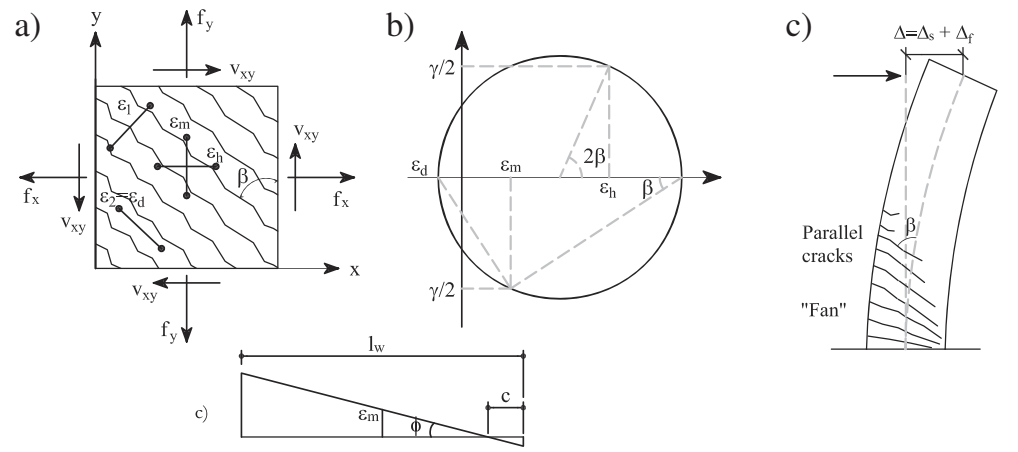

d)

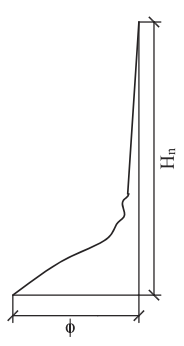

e)

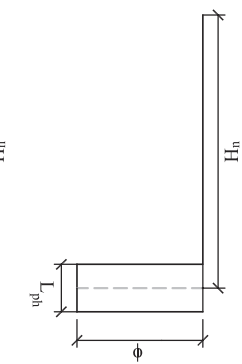

Figure 2. (a) Truss analogy model for reinforced concrete elements with parallel compression struts; (b) Mohr's circle, representing the strain state at the centre line of the wall; and (c) strain profile showing $\varepsilon_{m}$ and $\phi$. Plastic hinge method: (d) crack pattern; (e) true curvature profile; and (f) plastic curvature profile assumed in plastic hinge method (Beyer et al., 2011).

$$
\gamma=\frac{\varepsilon_{m}}{\tan \beta}+\varepsilon_{h} \cdot \tan \beta-\frac{2 \cdot \varepsilon_{d}}{\sin 2 \beta}
$$

where $\varepsilon_{d}$ is the axial strain in the compression strut, $\varepsilon_{m}$ the mean axial strain, $\varepsilon_{h}$ the horizontal strain and $\beta$ the cracking angle measured against the element axis. Only three out of the five parameters $\varepsilon_{d}, \varepsilon_{m}, \varepsilon_{h}$, $\beta$ and, $\gamma$ are required to determine the Mohr's circle of strains and the other two can be expressed as functions. The form of Eq. (1) is chosen because it visualizes the effect of the cracking angle $\beta$ on the three different contributions to the shear strain $\gamma$ : The first term represents the contribution of the mean axial strain $\varepsilon_{m}$. In structural walls subjected to seismic loading, the axial strains are chiefly caused by flexural deformations. Given that the depth $c$ of the compression zone remains approximately constant once the section has yielded, $\varepsilon_{m}$ is directly related to the curvature $\varphi$, which determines the flexural deformations. Therefore, the shear strains are directly related to the flexural deformations. The second and third terms represent the contributions of the horizontal strains in the shear reinforcement and of the strain in the compression diagonal to the shear strain $\gamma$. For slender RC walls, which behaviour is dominated by the flexural response and which shear resisting mechanisms do not significantly degrade, the second and third terms may be considered as negligible (Beyer et al., 2011). Hence, the shear strain $\gamma$ can be approximated by a function of the curvature $\varphi$, the compression zone depth $c$ and the wall length $L_{w}$ (Figure 2c): 


$$
\gamma \approx \gamma_{f l}=\frac{\varepsilon_{m}}{\tan \beta}=\frac{\varphi \cdot\left(L_{w} / 2-c\right)}{\tan \beta}
$$

As the shear deformations are coupled to the axial strains, the shear strain of regions that remain elastic are rather small and will be neglected in the following. Assuming a constant curvature $\varphi$ and a mean axial strain $\varepsilon_{m}$ over the length of the plastic hinge $L_{p h}$, the shear displacement $\Delta_{\mathrm{s}}$ of the wall can be estimated as follows:

$$
\Delta_{s} \approx \gamma \cdot L_{p h} \approx \frac{\varphi \cdot\left(L_{w} / 2-c\right)}{\tan \beta} \cdot L_{p h}
$$

The flexural displacement $\Delta_{f}$, on the other hand, is calculated by assuming that all inelastic flexural deformations along the wall height $H_{n}$ can be ascribed to the plastic hinge mechanism:

$$
\Delta_{f} \approx H_{n} \cdot \varphi \cdot L_{p h}
$$

The ratio of shear to flexural displacement can therefore be written as follows:

$$
\frac{\Delta_{s}}{\Delta_{f}}=\frac{\left(L_{w} / 2-c\right)}{H_{n} \cdot \tan \beta}
$$

The neutral axis depth $c$ remains typically approximately constant after flexural yielding. Hence, Eq. (5) backs up the experimental observation that the ratio of shear to flexural displacements remains approximately constant over the entire range of inelastic response. The cracking angle $\beta$ can be estimated as follows (Collins and Mitchell, 1997):

$$
\beta=\tan ^{-1}\left(\frac{j d}{V} \cdot\left(f_{l} \cdot b_{w}+\frac{A_{s w} \cdot f_{y w}}{s}\right)\right)<90^{\circ}
$$

where $j d$ is the lever arm between the compression and tensile resultant, $V$ is the shear force, $f_{l}$ is the tensile strength perpendicular to the crack, which can be estimated as a function of the cracking stress and the strain orthogonal to the crack, $b_{w}$ is the wall thickness, and $A_{s w}, f_{y w}$ and $s$ are the area, the yield strength and the spacing of the transverse reinforcement, respectively.

\section{BEAM-COLUMN FINITE ELEMENT WITH SHEAR-FLEXURE INTERACTION}

The constitutive law for shear-flexure interaction in capacity-designed slender RC walls that was developed in Section 2 is implemented in a beam-column element. The finite element was originally developed for RC column members with substandard detailing (Mergos and Kappos, 2012a) and consists of two sub-elements accounting for flexural and shear response, respectively. These subelements are discussed in the following. Emphasis is placed on the procedures developed to account for shear-flexure interaction.

\subsection{General formulation}

The proposed beam element is based on the flexibility approach (force-based element) and belongs to the class of phenomenological member-type models. It consists of two sub-elements representing the flexural response and shear response of the RC member, respectively (Figure 3). The total flexibility 


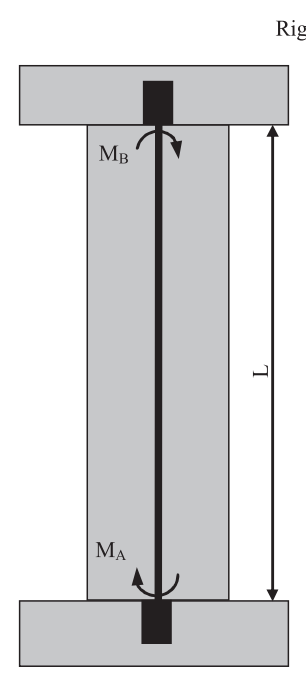

(a)

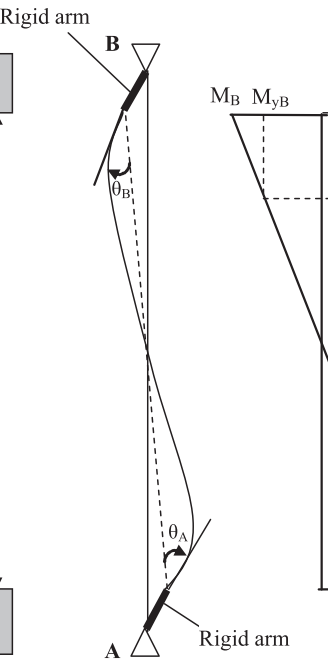

(b) (c)

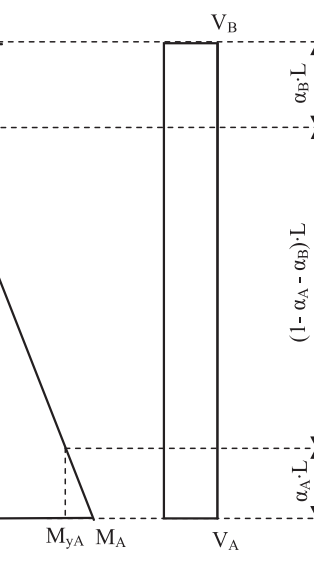

(d)

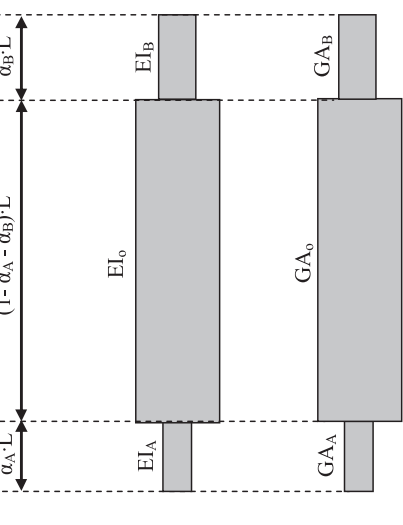

(e)

Figure 3. Beam-column element with shear-flexure interaction: (a) reinforced concrete wall; (b) finite element; (c) moment diagram; (d) shear diagram; (e) flexural sub-element; and (f) shear sub-element.

matrix $F$ is calculated as the sum of the flexibilities of its sub-elements for shear and flexure and can be inverted to produce the element stiffness matrix $K$ (Park et al., 1987; Lobo, 1994). Hence,

$$
F=F^{f l}+F^{s h}
$$

$$
K=F^{-1}
$$

where, $F, F^{f}$ and $F^{\text {sh }}$ are the total, flexural and shear tangent flexibility matrices. $K$ is the tangent stiffness matrix of the element, relating the incremental beam end moments $\Delta M_{A}, \Delta M_{B}$ to the beam end rotations $\Delta \theta_{A}$ and $\Delta \theta_{B}$ (Figure 3 ) through the following equation:

$$
\left[\begin{array}{c}
\Delta M_{A} \\
\Delta M_{B}
\end{array}\right]=K \cdot\left[\begin{array}{c}
\Delta \theta_{A} \\
\Delta \theta_{B}
\end{array}\right]
$$

The local stiffness matrix, relating displacements and forces at the element joints, is determined following standard structural analysis procedures (Reinhorn et al., 2009). A constant elastic axial stiffness is assumed throughout the response. Axial force-bending moment interaction is not accounted for in the beam element formulation. Hence, the application of the model is restricted to cases for which no significant axial load variation is expected.

In the original formulation of the finite element an additional sub-element, connected in series with the flexural and shear sub-element, is employed to account for anchorage slip fixed-end rotations developed in RC column members (Mergos and Kappos, 2012a). However, for typical slender RC walls, fixed-end rotations may be omitted or smeared into flexural rotations, because the contribution of anchorage slip deformation to the total deformation is typically small. The components of the beam element, as well as their interaction, are described in the following sections. 


\subsection{Flexural sub-element}

The flexural sub-element (Figure 3e) models the flexural behaviour of the RC member. It consists of a set of rules governing the hysteretic moment-curvature $(M-\varphi)$ response of the member end sections and a spread inelasticity model describing the flexural stiffness distribution along the length of the member. The $M-\varphi$ hysteretic model is composed of the envelope curve in Figure $4 \mathrm{a}$ and a set of rules determining the response during unloading and reloading. The $M-\varphi$ envelope curve is derived from section analysis and appropriate bilinearization. The cyclic response is described by the hysteretic model by Sivaselvan and Reinhorn (1999), which has been modified in order to be compatible with a bilinear envelope curve (Mergos and Kappos, 2012a, Figure 4b). The cyclic degradation parameters are chosen to match the response of five slender RC structural walls tested by Dazio et al. (2009). The values obtained for the parameters describing the unloading stiffness degradation and the slip or crack closing are 4.0 and 0.75 , respectively (Reinhorn et al., 2009).

To capture the variation of the flexural stiffness along the concrete member, a spread inelasticity model is assigned (Soleimani et al., 1979). To do so, the element is divided into two inelastic end regions and one elastic intermediate zone. The stiffness of the intermediate zone is assumed to be uniform and equal to the initial branch of the $M-\varphi$ envelope curve that corresponds to the elastic stiffness $E I_{O}$ of the cracked member. The flexural stiffness in the inelastic end zones is defined by the flexural rigidities $E I_{A}$ and $E I_{B}$, which are determined from the $M-\varphi$ hysteretic relationships of the end sections (Figure 3e). The normalized lengths of these end zones are $\alpha_{A}$ and $\alpha_{B}$, which are referred to as inelastic length coefficients. They are determined from the instantaneous moment diagrams as the length of the element where acting moments exceed the end section yield moments $M_{y A}$ and $M_{y B}$. Analytical expressions for the yield penetration coefficients under double and single bending conditions can be found in Reinhorn et al. (2009). The element formulation does therefore not account for the influence of inclined shear cracks on the curvature distribution, which is an inherent shortcoming of force-based inelastic beam elements.

Having established the stiffness distribution along the RC member, the coefficients of the flexibility matrix of the flexural sub-element can be derived by closed form equations determined from virtual work principles (Soleimani et al., 1979; Lobo, 1994).

\subsection{Shear sub-element}

\subsubsection{Formulation}

The shear sub-element (Figure 3f) represents the hysteretic shear behaviour of the RC member prior and subsequent to shear cracking and flexural yielding. It consists of a set of rules determining the $V-\gamma$ hysteretic behaviour of the member's intermediate and end regions, and a shear spread inelasticity model that describes the distribution of shear stiffness along the RC member. The shear hysteresis is determined by the $V-\gamma$ envelope (Figure $5 \mathrm{a}$ ) and a set of rules describing the response during unloading and reloading (Figure 5b).

a)

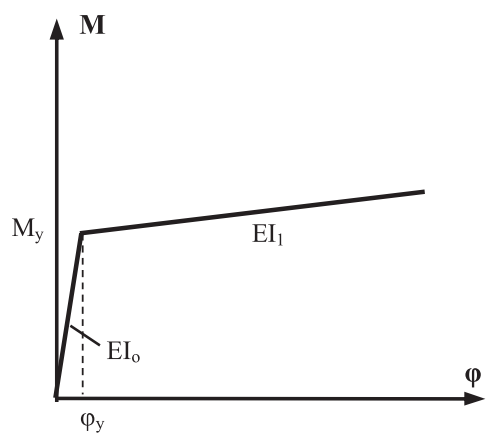

b)

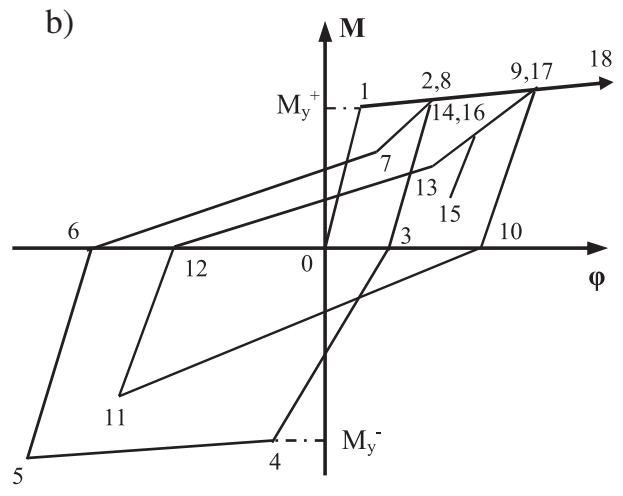

Figure 4. Moment-curvature (M- $\phi$ ) hysteretic response: (a) bilinear envelope curve; and (b) hysteretic model. 
a)

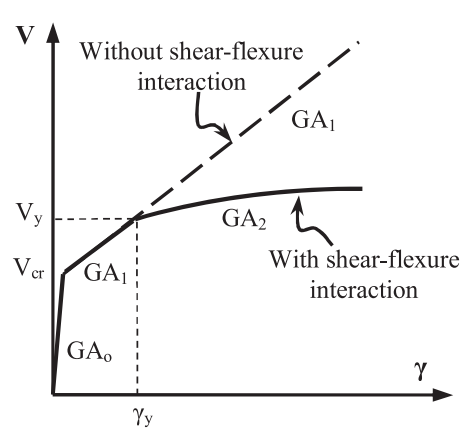

b)

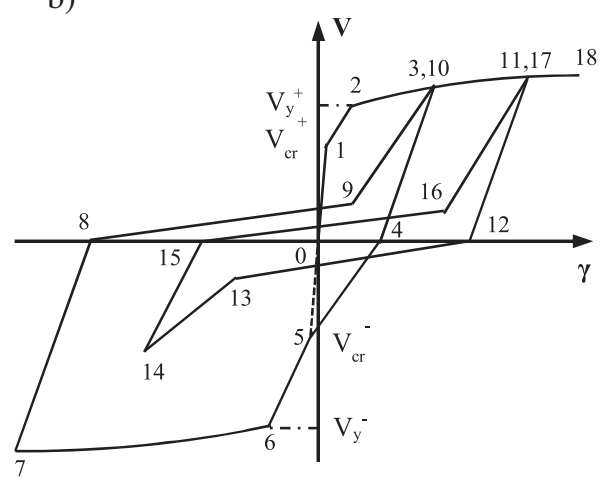

Figure 5. Shear force-shear strain $(V-\gamma)$ hysteretic response: (a) initial and modified envelope curve; and (b) hysteretic model.

Equivalent to the flexural sub-element, the shear sub-element is divided into two end zones, in which shear-flexure interaction is considered, and an intermediate region, where the interaction with flexure may be disregarded. The lengths of the inelastic end zones $\alpha_{A}$ and $\alpha_{B}$ of the shear sub-element are the same as those of the flexural sub-element. This formulation assures that shear deformations in slender RC walls are concentrated in the plastic zones (Beyer et al., 2011).

The shear stiffness of the intermediate part of the sub-element is assumed to be uniform and is derived by the application of the $V-\gamma$ envelope without shear-flexure interaction (Figure 5a). This envelope is composed of two branches. The first branch, with uncracked shear stiffness $G A_{o}$, connects the origin and the point associated with shear cracking $\left(\gamma_{c r}, V_{c r}\right)$. The force $V_{c r}$ at which shear cracking occurs is estimated as the shear resistance of members not requiring shear reinforcement (CEN, 2004a). The shear stiffness $G A_{o}$ is computed as the shear stiffness of an elastic homogenous section. The second branch of the envelope characterizes the shear stiffness $G A_{1}$ of the member after shear cracking $\left(\gamma_{c r}, V_{c r}\right)$ and prior to the onset of flexural yielding $\left(\gamma_{y}, V_{y}\right)$. The shear stiffness $G A_{l}$ is calculated such that at the onset of flexural yielding the ratio of shear to flexural deformations $\left(\Delta_{s} / \Delta_{f}\right)$ corresponds to the $\Delta_{s} / \Delta_{f}$-ratio estimated with the model presented in Section 2.

The shear stiffness of the inelastic end zones is determined by the application of the $V$ - $\gamma$ envelope accounting for shear-flexure interaction effects (Figure 5a). This envelope curve is composed of three branches. The first two branches correspond to those of the $V-\gamma$ envelope without interaction. The stiffness of the third branch $\mathrm{GA}_{2}$ is computed such that the shear-flexure interaction constitutive law of Section 2 is satisfied. This is achieved by linking the shear stiffness $G A_{2}$ to the maximum curvature demand on the respective end section of the flexural sub-element. The methodology for deriving the shear stiffness $G_{2}$ after flexural yielding for slender RC walls is described in the following section.

As for the flexural response, the hysteresis model by Sivaselvan and Reinhorn (1999) is used for describing the shear stiffness during unloading and reloading. However, because shear hysteretic response is characterized by significant pinching and stiffness deterioration (Ozcebe and Saatcioglu, 1989), the cyclic degradation parameters are assumed to be more severe than for the flexural response. The shear cyclic degradation parameters are again chosen to match the experimental $V-\gamma$ results of five slender RC structural walls tested by Dazio et al. (2009). The derived values are 1.0 for the unloading stiffness degrading parameter and 0.3 for the slip or crack-closing parameter (Reinhorn et al., 2009). Having established the stiffness distribution along the RC member, the coefficients of the flexibility matrix of the shear sub-element are derived by closed form equations determined from the virtual work principles (Mergos and Kappos, 2009, 2012a).

3.3.2. Tangent shear stiffness in the plastic hinge regions for walls under general loading conditions The total shear flexibility in the plastic hinge regions after flexural yielding may be considered as the sum of the shear flexibility prior to flexural yielding and the additional shear flexibility induced by shear-flexure interaction. Hence, it is 


$$
\Delta \gamma=\Delta \gamma_{s h}+\Delta \gamma_{f l}
$$

where $\Delta \gamma$ is the total shear strain increment after flexural yielding, $\Delta \gamma_{s h}$ is the shear strain increment due to shear flexibility prior to flexural yielding and $\Delta \gamma_{f}$ is the shear strain increment developed by interaction with flexure. The shear flexibility prior to flexural yielding is equal to $1 / G A_{1}$ (Figure 5a). If $\Delta V$ is the applied shear force increment, the tangent shear stiffness $G A_{2}$ after the onset of flexural yielding can be computed as follows:

$$
\Delta \gamma=\Delta \gamma_{s h}+\Delta \gamma_{f l} \rightarrow \frac{\Delta V}{G A_{2}}=\frac{\Delta V}{G A_{1}}+\Delta \gamma_{f l} \rightarrow G A_{2}=\frac{\Delta V}{\Delta V+\Delta \gamma_{f l} G A_{1}} \cdot G A_{1}
$$

The shear strain increment developed by interaction with flexure $\Delta \gamma_{\mathrm{fl}}$ can be calculated using Eq. (12), which corresponds to the incremental form of Eq. (2).

$$
\Delta \gamma_{f l}=\frac{\Delta \varphi \cdot\left(L_{w} / 2-c\right)}{\tan \beta}
$$

Furthermore, for the vast majority of flexure dominated RC walls, the shear flexibility $1 / G A_{l}$ prior to flexural yielding may be disregarded, because it represents only a small fraction of the total shear response (Beyer et al., 2011). By applying this simplification and substituting Eq. (12) into Eq. (11), $G A_{2}$ can be expressed as a function of $\Delta \varphi$, which is the difference between the new and the previous maximum curvature in the same direction of loading, and the corresponding increment in shear force $\Delta V$. At all times, $G A_{2}$ should be smaller than $G A_{1}$ :

$$
G A_{2}=\frac{\Delta V}{\Delta \gamma_{f l}}=\frac{\Delta V \cdot \tan \beta}{\Delta \varphi \cdot\left(L_{w} / 2-c\right)} \leq G A_{1}
$$

Equations (11-13) express the instantaneous tangent shear stiffness $G A_{2}$ as a function of $G A_{1}, \Delta V$ and $\Delta \varphi$. Hence, no assumptions regarding the moment distribution are required and the equation for $G A_{2}$ is therefore valid for general loading conditions. However, in structural analysis, $G A_{2}$ also affects $\Delta V$ and $\Delta \varphi$, because it influences the total flexibility matrix of the element. Hence, an iterative solution algorithm is adopted, which is outlined in Figure 6.

Equation (12) assumes a constant compression zone depth $c$ after the onset of flexural yielding and yields a linear variation of $\gamma_{f}$ with $\varphi$. For well detailed RC walls, this assumption is typically adequate. However, the proposed procedure can be easily modified to account for a variation of $c$ : To do so, $\Delta \gamma_{f l}$ in Eq. (13) is calculated as the increment of $\gamma_{f f}$ from two subsequent analysis steps. In this case, $\gamma_{f}$ is calculated by means of Eq. (2), by using always the actual value of neutral axis depth $c$ corresponding to curvature $\varphi$.

Typically, the algorithm converges fast. The number of iterations may increase as the influence of shear deformations on the element flexibility increases. Considering that this iterative scheme is applied only to a limited number of steps in the numerical analysis, the additional computational cost may be regarded as negligible when compared with analyses with constant member shear stiffnesses.

\subsubsection{Tangent shear stiffness for cantilever walls}

For cantilever walls, the shape of the bending moment and shear force diagram remains constant throughout the response. This section shows that for this special loading condition Eq. (13) can be simplified further. For the cantilever wall in Figure 7, the shear force increment $\Delta V$ can be written as $\Delta M / H_{n}$. Hence, Eq. (13) becomes 


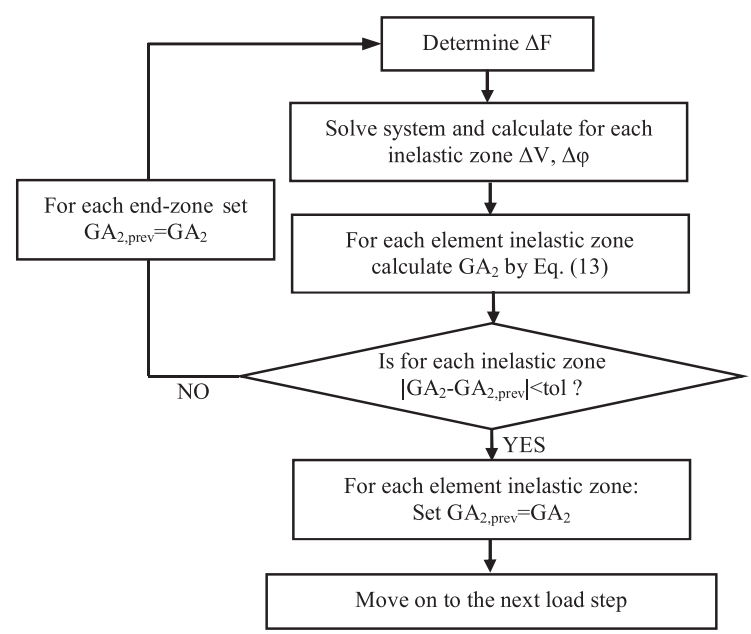

Figure 6. Proposed iterative scheme for determining $\mathrm{GA}_{2}$ under general loading conditions.
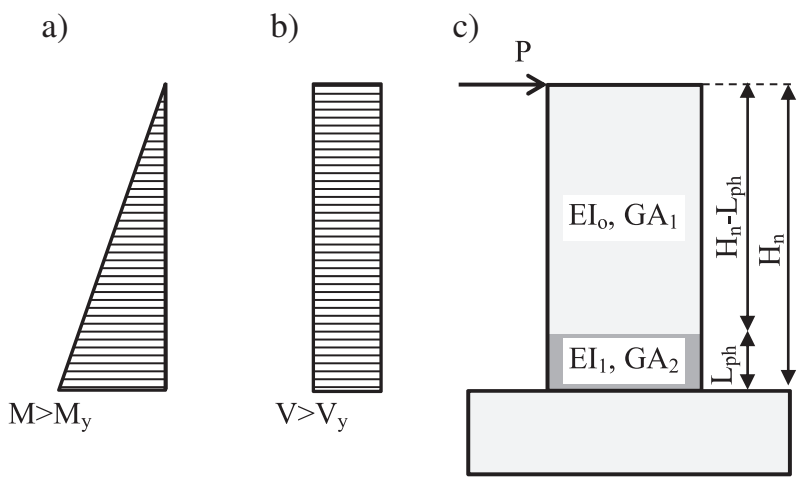

Figure 7. Cantilever wall: (a) moment diagram; (b) shear force diagram; and (c) flexural and shear stiffness distribution after shear cracking and flexural yielding under monotonic loading.

$$
G A_{2}=\frac{\Delta M \cdot \tan \beta}{\Delta \varphi \cdot\left(L_{w} / 2-c\right) \cdot H_{n}}
$$

After the onset of flexural yielding, the ratio $\Delta M / \Delta \varphi$ represents the tangent stiffness $E I_{l}$ of the $M-\varphi$ envelope (Figure 4a). Substituting $\Delta M / \Delta \varphi$ by $E I_{1}$, Eq. (14) becomes

$$
G A_{2}=\frac{E I_{1} \cdot \tan \beta}{\left(L_{w} / 2-c\right) \cdot H_{n}}
$$

Equation (15) shows that for slender RC cantilever walls, a constant tangent shear stiffness $G A_{2}$ may be assigned to the plastic hinge regions after the onset of flexural yielding in order to account for shear-flexure interaction. It is emphasized that the equations above are valid irrespective of the plastic hinge length $L_{p h}$. The equation holds if the compression zone depth can be approximated with a reasonable accuracy by a constant value $c$.

Equation (15) may also be rewritten as a function of the ratio of shear to flexural displacements $\Delta_{s} / \Delta_{f}$, which is approximately independent of the imposed ductility demand (Beyer et al., 2011). Substituting Eq. (5) into Eq. (15): 


$$
G A_{2}=\frac{E I_{1}}{\left(\frac{\Delta_{s}}{\Delta_{f}}\right) \cdot H_{n}^{2}}
$$

Figure $7 \mathrm{c}$ presents the proposed flexural and shear stiffness distribution over the height of the cantilever wall after shear cracking and flexural yielding. It is supposed that the wall is subjected to a monotonically increasing lateral load $P$. Outside the plastic hinge region, where shear-flexure interaction is neglected, the elastic flexural stiffness $E I_{o}$ and the cracked shear stiffness $G A_{l}$ are assigned. Inside the plastic hinge length $L_{p h}$, the post-yielding tangent flexural stiffness $E I_{1}$ and the tangent shear stiffness with shearflexure interaction $G A_{2}$ have to be applied.

For single cantilever walls, the shear strain distribution along the height of the wall may not be important when local deformations are not examined. For these cases, the shear stiffness distribution of Figure $7 \mathrm{c}$ can be substituted by a uniform shear stiffness value $G A_{3}$, which is valid after the onset of flexural yielding. The definition of $G A_{3}$ is also useful for conventional finite element formulations, which assume uniform shear stiffness along the length of the element. The uniform shear stiffness $G A_{3}$ can be computed on the basis of the hypothesis that both shear stiffness distributions yield the same tip shear displacement increment $\delta_{s}$ for a shear force increment $\Delta V$ :

$$
\delta_{s}=\frac{\Delta V}{G A_{3}} \cdot H_{n}=\frac{\Delta V}{G A_{2}} \cdot L_{p h}+\frac{\Delta V}{G A_{1}} \cdot\left(H_{n}-L_{p h}\right)
$$

Solving for $G A_{3}$, one obtains the following:

$$
G A_{3}=\frac{G A_{1} \cdot G A_{2} \cdot H_{n}}{G A_{1} \cdot L_{p h}+G A_{2} \cdot\left(H_{n}-L_{p h}\right)}
$$

\section{VALIDATION AGAINST EXPERIMENTAL RESULTS OF SLENDER REINFORCED CONCRETE WALLS}

The proposed model is implemented in the general finite element code IDARC2D developed at the State University of New York at Buffalo (Reinhorn et al., 2009). To examine its performance, the numerical results are compared with experimental results obtained from a quasi-static cyclic test of a rectangular RC wall (WSH3 in Dazio et al., 2009). The test unit was $2.00 \mathrm{~m}$ long and $0.15 \mathrm{~m}$ wide and had a shear span of $4.56 \mathrm{~m}$ (Figure 8a). During cyclic loading, the specimen was subjected to a constant axial load of $686 \mathrm{kN}$. Further details on reinforcement configuration and material properties can be found in Dazio et al. (2009).

The test unit is modelled with a single finite element. The length of the inelastic end zones is assumed constant, and, rather than computing $\alpha_{A}$ from the spread of inelasticity, $\alpha_{A}$ is computed from the plastic hinge length equation for RC walls in Priestley et al. (2007). Because the plastic hinge length equation comprises a strain penetration term, anchorage slip is indirectly taken into consideration. As the wall is only yielding at its base, $\alpha_{B}$ is equal to zero. The shear stiffness $G A_{2}$ of the plastic hinge was computed from Eq. (15) and the crack angle $\beta$ was estimated from Eq. (6).

Figure $8 \mathrm{~b}$ presents the lateral load versus lateral displacement response obtained from the numerical model and the test. It can be seen that the numerical model reproduces with sufficient accuracy the experimentally obtained initial stiffness, lateral load capacity as well as unloading and reloading stiffness.

Furthermore, Figure $8 \mathrm{c}$ presents a comparison of the predicted and the recorded lateral top displacement developed by shear deformations. This figure underlines that experimental shear displacements continue to increase after flexural yielding and constitute a considerable part of the total response. The proposed model predicts the experimentally obtained shear response in an adequate manner. 
a)

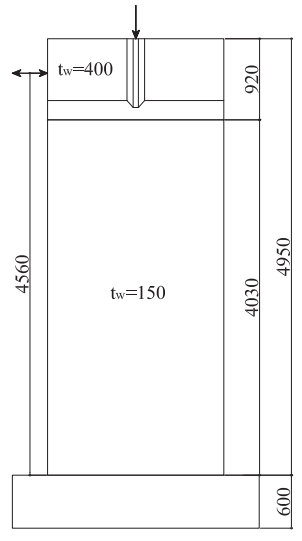

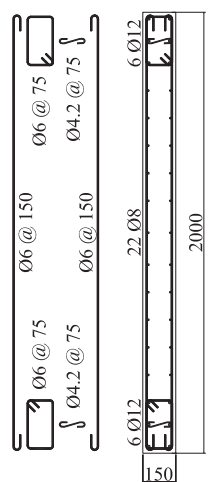
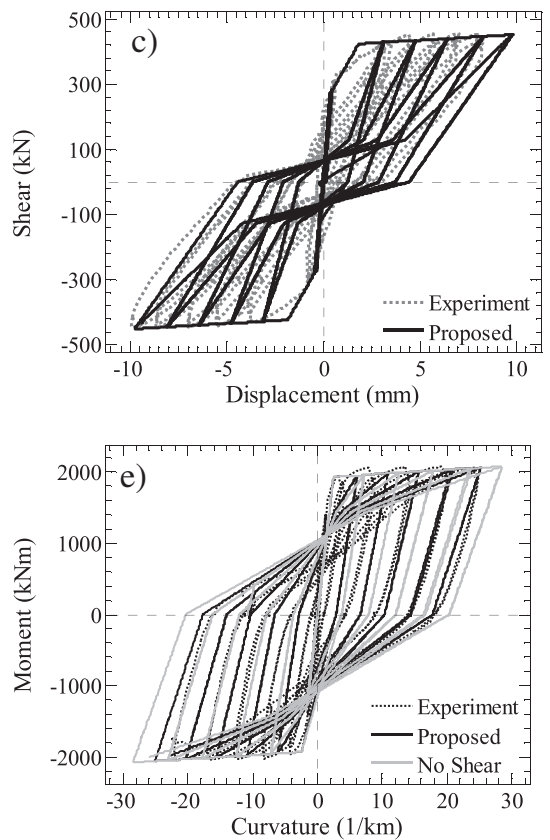
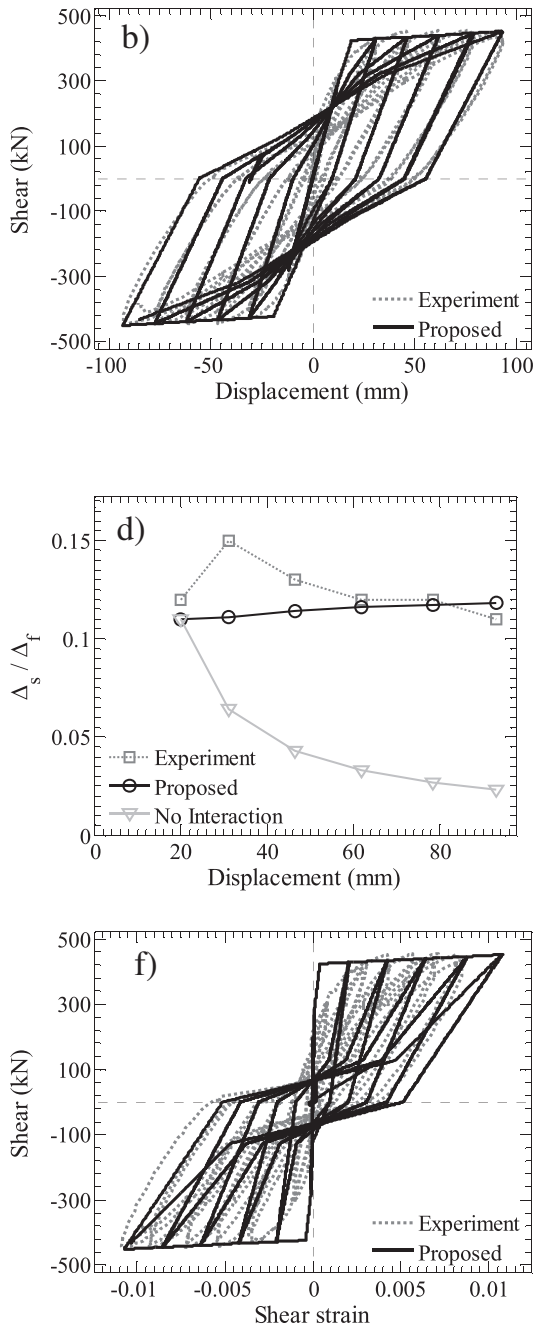

Figure 8. RC structural wall WSH3 by Dazio et al. (2009): (a) structural configuration; (b) shear force versus total displacement; (c) shear force vs. shear displacement; (d) variation of shear-to-flexural displacement ratio with imposed top displacement demand; (e) base moment vs. curvature; and (f) shear force versus distortion in the plastic hinge region.

Figure 8d illustrates the variation of the shear-to-flexure displacement ratio with the imposed top displacement demand. As outlined in Section 2, the experimental ratio remains approximately constant. This is well represented by the proposed model, which considers shear-flexure interaction. If shear-flexure interaction is neglected, the $\Delta_{s} / \Delta_{f}$-ratio decreases with increasing ductility demand and therefore at larger ductility demands the actual $\Delta_{s} / \Delta_{f}$-ratio is significantly underestimated. It is worth noting that, even when modelling shear-flexure interaction, $\Delta_{s} / \Delta_{f}$ does not remain exactly constant as inelastic deformations increase. This is due to the influence of the flexural and shear deformations outside the plastic hinge region. However, it is clear that this deviation is insignificant and may be disregarded in the analytical procedure.

Figure $8 \mathrm{e}$ presents a comparison of the experimental and analytical base moment versus base curvature response as derived by the proposed analytical model and as derived by a simplified model, which does not consider shear deformations at all. The figure shows that the proposed model predicts well the experimental base curvature response while the model without shear flexibility considerably overestimates base curvature demands. Finally, Figure $8 \mathrm{f}$ compares the experimental and analytically predicted 
shear strains in the plastic zone. Given the complexity of the phenomenon and the uncertainties included in the analytical procedure and the experimental measurements, the proposed model predicts the experimental values with reasonable accuracy.

\section{CASE STUDIES WITH THE NEW BEAM ELEMENT}

The newly implemented element is applied in the numerical analysis of structures with slender RC walls. Three different case studies including pushover and time-history analyses are presented. These comprise a single RC wall with a varying height of contraflexure (Section 5.1), a pushover analysis of interconnected cantilever walls of different length (Section 5.2) and pushover and time-history analyses of a wall-frame structure (Section 5.3). All case studies investigate the sensitivity of the analysis results with regard to modelling assumptions for shear deformations.

\subsection{Pushover analysis of a single reinforced concrete wall with varying point of contraflexure}

This section investigates the ability of the numerical model to capture shear-flexure interaction when the height of contraflexure varies during the structural response (Figure 9). As an example, the test unit WSH3 of the previous section is assumed to have twice its original height and to be rotationally restrained at the top (Figure 10a). The $M-\varphi$ characteristics of the base wall section are the same as for WSH3. The top section has the same elastic flexural stiffness but a significantly higher yield moment than the bottom section, preventing flexural yielding at the top throughout the analysis. The wall is subjected to an increasing horizontal force until 3\% lateral drift is reached. It is expected to behave as test unit WSH3 until the onset of flexural yielding at its base. From this point onwards, the bending moment distribution changes and the point of contraflexure moves from the midheight towards the wall base. The reduction of the height of contraflexure affects the ratio of shear to flexural deformations of the wall.

Three beam element models are used with different capabilities concerning capturing shear-flexure interaction: The first model neglects any shear-flexure interaction but assumes a constant shear stiffness $G A_{1}$ subsequent to shear cracking. The second model considers shear-flexure interaction but assumes that the height of zero moment $H_{n}$ remains constant and equal to its value at the onset of flexural yielding $\left(H_{n 0}=4.56 \mathrm{~m}\right)$. The third model accounts for shear-flexure interaction as well as the change of the height of contraflexure (proposed model). In all models, the length of the inelastic zone at the base of the wall is computed from the current moment diagram following the gradual spread plasticity approach in order to account for the variation of the height of contraflexure (Mergos and Kappos, 2012a).

Figure $10 \mathrm{~b}$ presents the variation of the height of contraflexure $H_{n}$ with imposed lateral drift. The height of contraflexure is normalized by the total wall height $H_{t o t}=9.12 \mathrm{~m}$. For all three models, $H_{n}$ reduces gradually from $H_{t o t} / 2$ prior to yielding at the base to approximately $H_{t o t} / 4$ at $3 \%$ lateral drift. As a result of the variation of $H_{n}$, the relationship between shear force and base curvature becomes nonlinear (Figure 10c). As expected, the three models yield similar results with regard to the shear force-base curvature relationship (Figure 10c) but very different results with respect to shear deformations: The model that neglects shear-flexure interaction yields very small shear strains at the base of

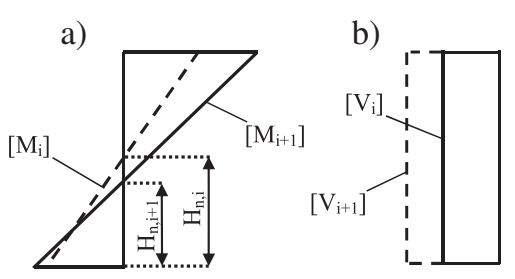

Figure 9. Case study of a wall member with varying height of contraflexure: (a) bending moment diagram; and (b) shear force diagram in two subsequent analysis steps. 
a)
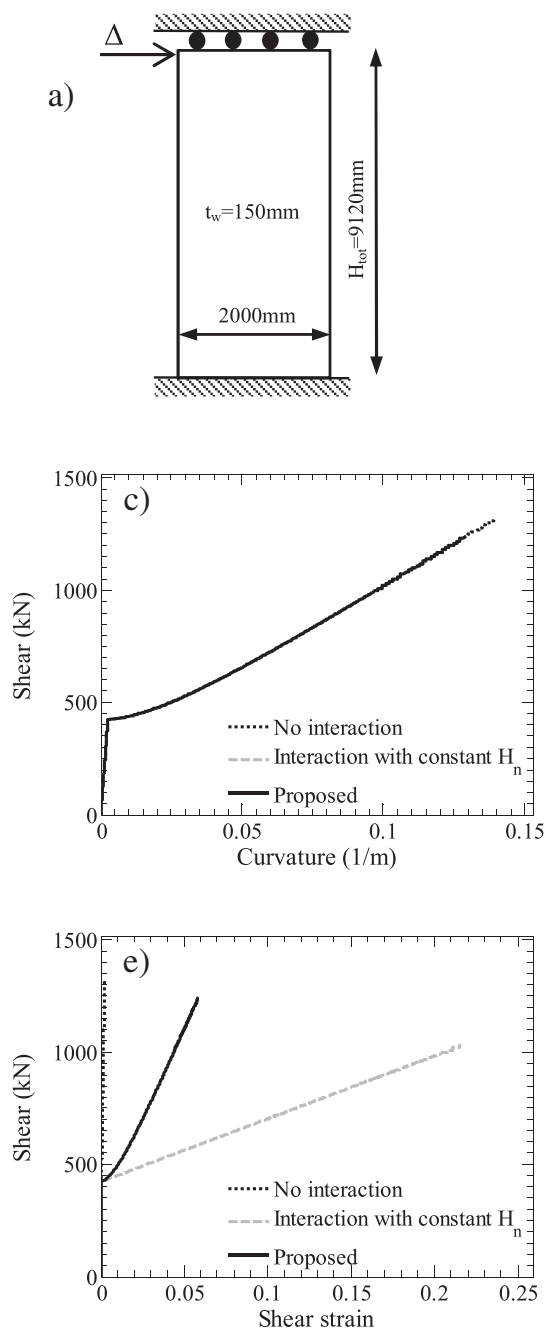
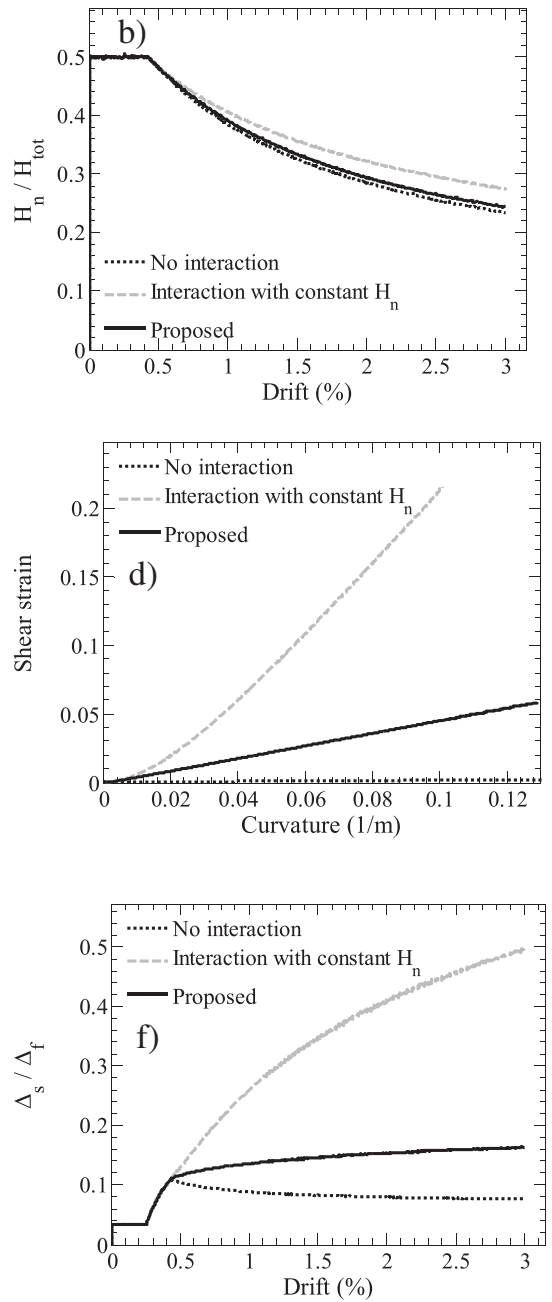

Figure 10. Reinforced concrete structural wall in double bending: (a) structural configuration; (b) variation of cantilever height with lateral drift; (c) shear force versus base curvature; (d) base shear strain versus base curvature; (e) shear force versus base shear strain; and (f) variation of shear-to-flexural top displacement ratio with lateral drift.

the RC wall. If the change of zero moment height $H_{n}$ is neglected when computing the shear stiffness $G A_{2}$, one obtains a linear relationship between shear force and shear strain after the onset of flexural yielding (Figure 10e). Because the relationship between shear force and base curvature is nonlinear (Figure 10c), this leads to a nonlinear relationship between base curvature and base shear strain (Figure 10d), which is not consistent with Eq. (2). Because $G A_{2}$ is inversely proportional to $H_{n}$ (Eq. 15) and $H_{n}$ decreases during the structural response, this model overestimates the base shear strains.

On the other hand, the proposed model is consistent with Eq. (2) and provides a linear relationship between base curvature and base shear strain, because the depth of the compression zone depth is assumed to be constant (Figure 10d). The resulting relationship between shear force and base shear strain is therefore nonlinear (Figure 10e).

Figure 10f presents the variation of the ratio of shear to flexural displacements at the top of the wall with the imposed lateral drift demand. Up to the onset of flexural yielding at the wall base, all models yield the same ratio. After yielding, the model that neglects shear-flexure interaction predicts a decrease of the $\Delta_{s} / \Delta_{f}$-ratio with increasing lateral drift. This contradicts Eq. (5) according to which $\Delta_{s} / \Delta_{f}$ tends to increase as $H_{n}$ decreases. The proposed model correctly predicts that $\Delta_{s} / \Delta_{f}$ increases with increasing lateral drift. The final ratio lies between the $\Delta_{s} / \Delta_{f}$-ratios of 0.11 and 0.22 that correspond to 
the ratios predicted by Eq. (5) for $H_{n}=H_{t o t} / 2$ and $H_{n}=H_{t o t} / 4$, respectively. The model that accounts for shear-flexure interaction but does not consider the change in height of contraflexure largely overestimates the $\Delta_{s} / \Delta_{f}$-ratio when the height of contraflexure decreases.

\subsection{Pushover analysis of interconnected cantilever walls}

The tall wall structure examined herein has eight storeys and a total height of $24 \mathrm{~m}$ (Figure 11). It is braced by two RC walls with lengths of 6 and $4 \mathrm{~m}$, respectively. The RC walls are coupled at each storey level by a RC slab. In this study, the effect of gravity columns is not considered. The slabs are considered as infinitely stiff in-plane and infinitely flexible out-of-plane. Both walls have a width of $0.2 \mathrm{~m}$ and are designed according to EC8 (CEN, 2004b). The structure is subjected to a pushover analysis applying a uniformly distributed lateral load. The aim of this study is to examine the sensitivity of the wall base shears to modelling assumptions regarding the shear flexibility of the walls.

The structure is analyzed using three different equivalent frame models: The first model includes flexural deformations only. The second model accounts for flexural and shear deformations without considering their interaction. The proposed model accounts for shear-flexure interaction as described in Section 3.3. Due to the forces transmitted by the floor diaphragms, the wall moment distribution varies throughout the analyses. For this reason, after the onset of flexural yielding, Eq. (13) is used for computing the shear stiffness $G A_{2}$ and the length of the inelastic zone at the base of the wall is defined by the instantaneous moment diagram (Section 3.2). The results of the three models are compared with the predictions of a shell element model analyzed using the finite element program VecTor2 (Wong and Vecchio, 2002). VecTor2 is based on the modified compression field theory (Vecchio and Collins, 1986) and the disturbed stress field theory (Vecchio et al., 2001). Details on the analysis of the example structure with VecTor2 are given in Simonini et al. (2012). Because VecTor2 represents a rather refined analysis approach, it will serve as benchmark model for the results of the three equivalent frame models.

Figure 12 presents the base shear versus top displacement relationships of the entire structure, the long wall and the short wall as predicted by the three equivalent frame models and the VecTor 2 model. The system's response obtained from the three equivalent frame models is not sensitive to the modelling assumptions, and all three equivalent frame models yield results that are in close agreement with the prediction by VecTor2.

The shear force distribution between the long and the short wall, on the contrary, is rather sensitive to the modelling assumptions: The model, which does not account for the shear flexibility of the RC walls, yields base shear demands on the long and short wall that deviate significantly from the benchmark results by VecTor2. Considering the shear flexibility but neglecting the interaction between shear and flexural stiffness improves the prediction significantly at the onset of yielding of the long and short wall $(100-150 \mathrm{~mm})$. At this stage, the models with and without shear-flexure interaction yield similar results, because the shear flexibilities are the same (Figure 5a). However, for larger displacements, the

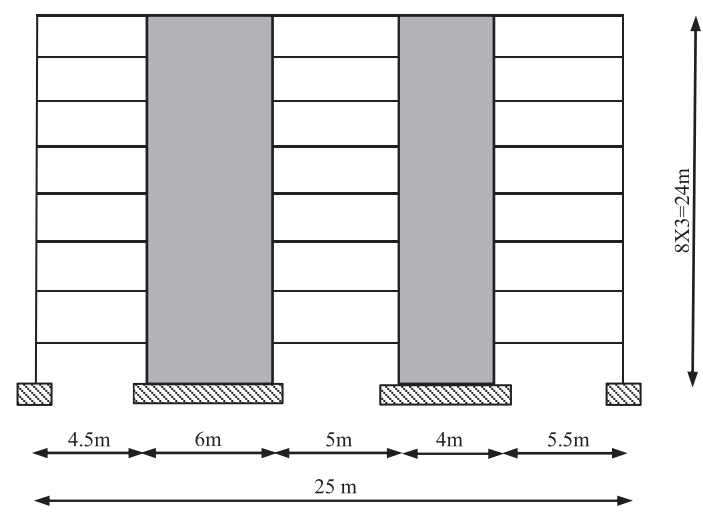

Figure 11. Geometry of the cantilever wall structure with two slender reinforced concrete walls of different lengths. 

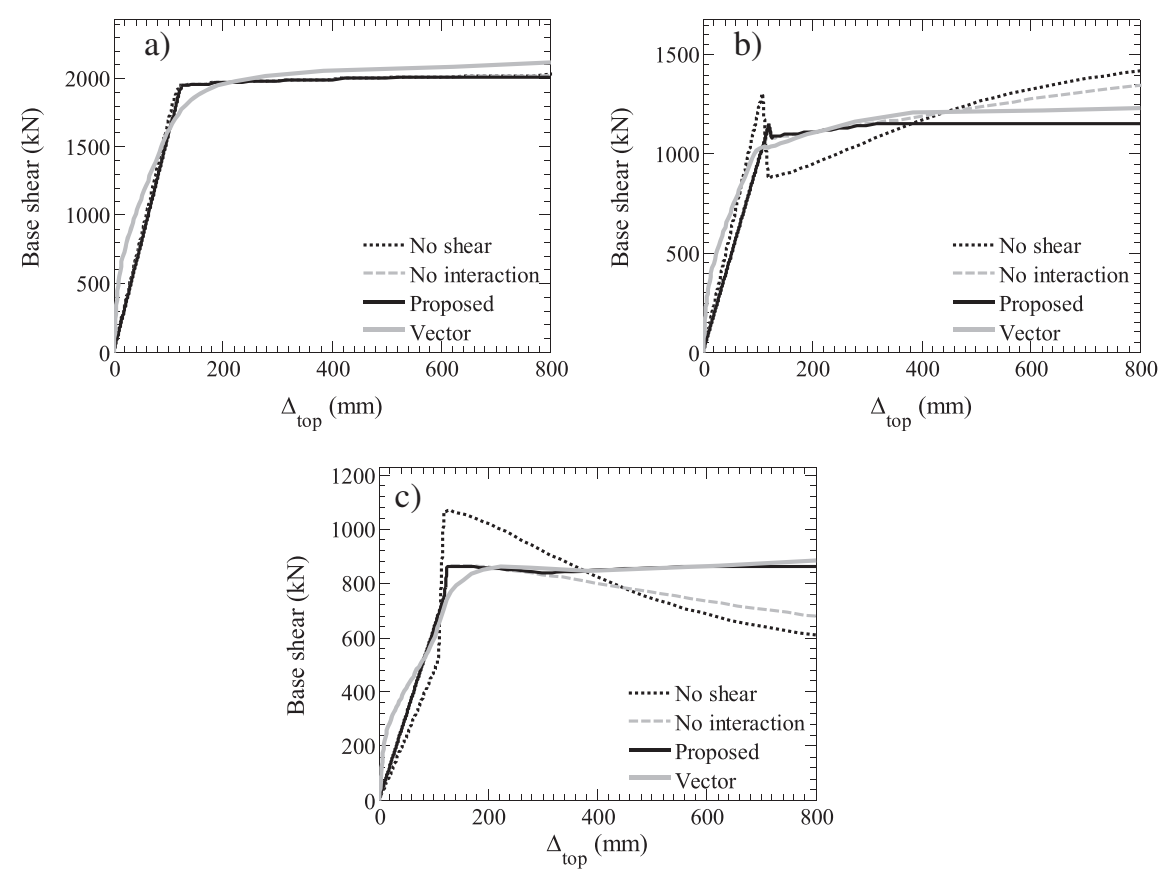

Figure 12. Base shear versus top displacement responses of the cantilever wall structure for the following: (a) the entire structure; (b) the long wall; and (c) the short wall.

model without interaction wrongly predicts that the base shear in the long wall increases while the base shear in the short wall decreases. This incorrect trend is eliminated if shear-flexure interaction is considered and the results of the proposed model are in good agreement with the benchmark results obtained from the VecTor2 model.

\subsection{Pushover and time history analyses of a tall wall-frame structure}

This section examines the effect of shear deformations on the response of a ten-storey wall-frame structure designed according to a previous version of EC8 for ductility class ' $\mathrm{M}$ '. The frame geometry is presented in Figure 13, and the design of the frame is described in Penelis and Kappos (1997).

Three different finite element models are applied for the seismic analysis of this frame. The first model includes flexural deformations only while the second model accounts for flexural and shear deformations but neglects their interaction. The proposed model accounts for shear-flexure interaction as outlined in Section 3.3. Because the wall moment distribution varies throughout the structural response, Eq. (13) is applied for computing the shear stiffness $G A_{2}$. The length of the inelastic zone at the base of the wall is defined by the instantaneous moment diagram following the gradual spread plasticity approach (Section 3.2). The main scope of this section is to investigate if shear-flexure interaction modifies the distribution of damage obtained from equivalent frame models for tall wall-frame structures.

Figure 14a shows that the shear flexibility has a negligible effect on the shape of the force displacement response of the wall-frame structure when subjected to lateral loading but increases the displacement capacity of the wall-frame system. Figure $14 \mathrm{~b}$ illustrates the drift profiles at a top displacement corresponding to an average drift of $2 \%$. The figure shows that the normalized drift of the base storey increases by approximately $30 \%$ when interaction is taken into account. This is due to the increase in inelastic shear deformations in the plastic hinge region. Unlike flexural displacements, which increase gradually over the height, inelastic shear displacements are concentrated in the plastic hinge regions. Additional shear deformations in the plastic hinge cause an increase in the curvature demand on the base columns (Figure14d) but have an insignificant effect on beam curvatures (Figure 14c). 


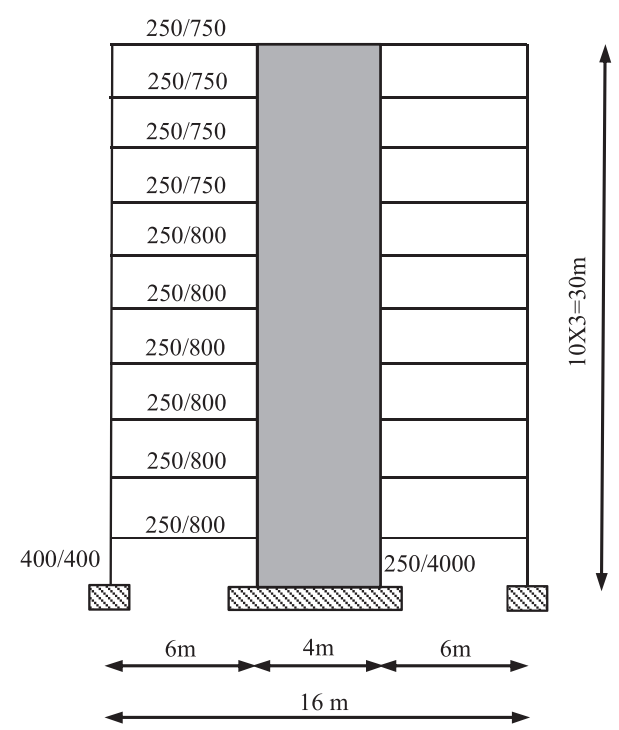

Figure 13. Geometry of the wall-frame structure.
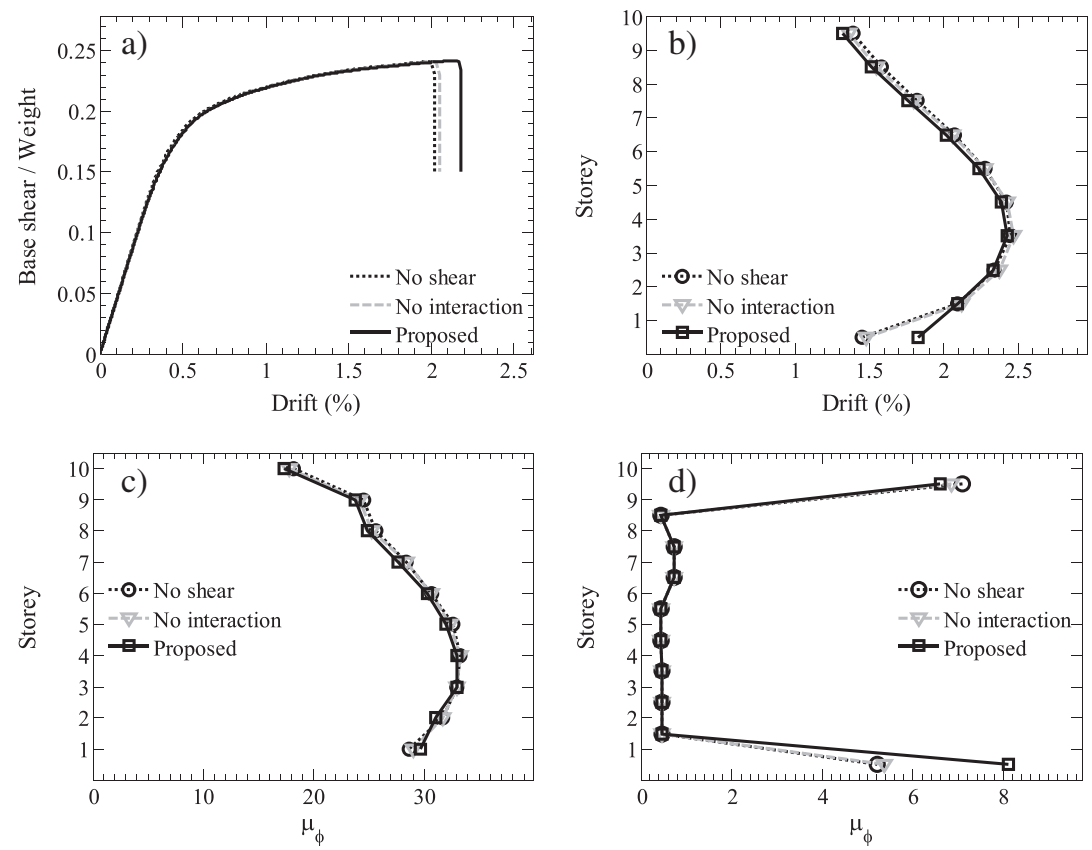

Figure 14. Pushover analysis results: (a) base shear over weight versus top displacement over total height; (b) maximum normalized interstorey drifts at $2 \%$ normalized top displacement demand; (c) maximum beam curvature ductility demands; and (d) maximum column curvature ductility demands at a top displacement corresponding to an average drift of $2 \%$.

Figure 15 illustrates the basic time history analysis results of this frame for the El-Centro $1940 \mathrm{~N}-\mathrm{S}$ ground motion record. The record is scaled up to a peak ground acceleration of $0.5 \mathrm{~g}$ in order to obtain significant damage for the frame under investigation. The trends observed from nonlinear time history analysis are similar to those obtained from pushover analysis: considering shear-flexure interaction increases the first storey drift (Figure 15b, c) and therefore the curvature ductility demand on the 

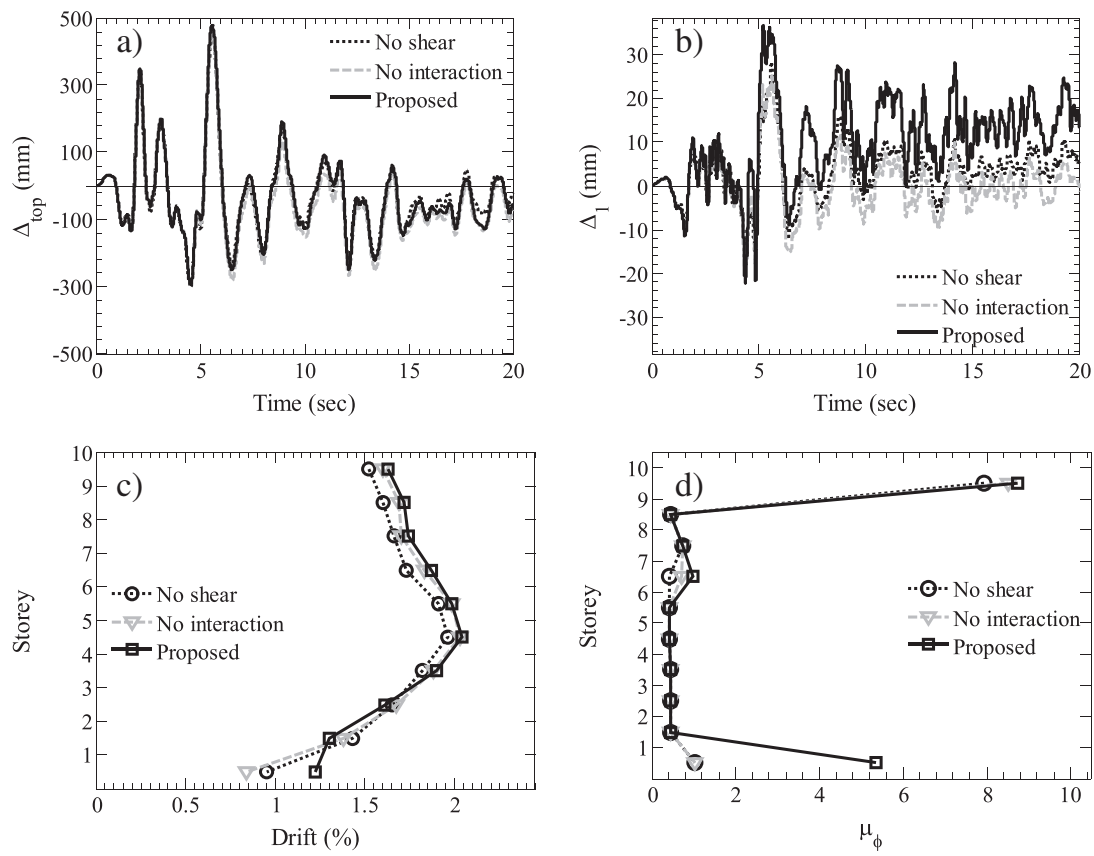

Figure 15. Inelastic time history analysis results for the El-Centro $1940 \mathrm{~N}-\mathrm{S}$ ground motion: (a) top lateral displacement response; (b) ground storey lateral displacement response; (c) maximum interstorey drift demands; and (d) maximum column curvature ductility demands.

column base that increases from 1.1 to 5.4 (Figure 15d). The shear flexibility, with and without interaction, has only a minor effect on the global response (Figure 15a).

\section{CONCLUSIONS}

Experimental results from quasi-static cyclic tests on RC walls have shown that shear deformations can constitute a significant ratio of the total deformations when the wall is loaded beyond the elastic regime. For cantilever walls, which form a stable flexural hinge at their base, the ratio of shear to flexural deformations remains approximately constant over the entire range of imposed displacement ductilities. This is contrary to the common modelling approach of treating shear deformation as decoupled from flexural deformations, which leads to constant shear deformations rather than a constant ratio of shear to flexural displacements once a flexural mechanism is formed and the shear force carried by the wall no longer increases.

This paper presents a methodology for incorporating shear-flexure interaction in the seismic analysis of structures with slender RC walls. Building on mechanics and experimental evidence, a phenomenological constitutive $V-\gamma$ law for the wall base section is proposed. The model is applicable for general loading conditions and can be simplified for the special loading condition of cantilever walls (constant shape of moment and shear profile). For the latter, a simple formula is proposed for determining a uniform average shear stiffness along the member length.

The modifications are implemented in a flexibility-based distributed inelasticity beam-column element composed of two interacting sub-elements (flexure and shear), which are connected in series. The element is implemented in IDARC2D, a general finite element framework for inelastic static and dynamic analysis of RC structures. The model is validated against global and local results from a quasi-static cyclic test of a RC wall. Inelastic static and dynamic analyses of tall wall and wall-frame structures were also employed to examine the effect of considering or neglecting shear-flexure interaction on global and local response quantities. The results of these analyses showed that considering shear-flexure interaction increases significantly the flexibility in the plastic hinge region. This led to 
an improved prediction of the base shear demand for the structure with walls of different length and increased curvature ductility demands on the column bases of the wall-frame structure. It is therefore recommended that shear-flexure interaction should be considered in the analysis if not only the global response of the system is of interest but if the analysis results are also used to assess the internal force distribution, local ductility demands or interstorey drifts.

\section{REFERENCES}

Beyer K, Dazio A, Priestley MJN. 2008. Quasi-static cyclic tests of two U-shaped reinforced concrete walls. Journal of Earthquake Engineering 12: 1023-1053.

Beyer K, Dazio A, Priestley MJN. 2011. Shear deformations of slender R/C walls under seismic loading. ACI Structural Journal 108: $167-177$.

CEN. 2004a. Eurocode 2: design of concrete structures - Part 1-1: general rules and rules for buildings. EN 1992-1-1:2004, European Committee for Standardisation, Brussels, Belgium.

CEN. 2004b. Eurocode 8: design of structures for earthquake resistance - Part 1: general rules, seismic actions and rules for buildings. EN 1998-1:2004, European Committee for Standardisation, Brussels, Belgium.

Collins MP, Mitchell D. 1997. Prestressed Concrete Structures. Response Publications: Ontario, Canada.

Dazio A, Beyer K, Bachmann H. 2009. Quasi-static cyclic tests and plastic hinge analysis of RC structural walls. Engineering Structures 31: 1556-1571.

Fardis MN. 2009. Seismic design, assessment and retrofitting of concrete buildings. Springer: London, UK.

Guner S, Vecchio FJ. 2010. Pushover analysis of shear-critical frames: formulation. ACI Structural Journal 107: 63-71.

Lobo RF. 1994. Inelastic dynamic analysis of reinforced concrete structures in three dimensions. PhD Thesis, University at Buffalo, State Univ. of New York, New York.

Marini A, Spacone E. 2006. Analysis of reinforced concrete elements including shear effects. ACI Structural Journal 103: 645-655.

Massone LM, Orakcal K, Wallace JW. 2006. Shear-flexure interaction for reinforced concrete walls. ACI Special Publication SP-236: $127-150$.

Mergos PE. 2011. Assessment of seismic behaviour of existing RC structures. PhD Thesis. Aristotle University of Thessaloniki, Thessaloniki, Greece.

Mergos PE, Kappos AJ. 2009. Modelling gradual spread of inelastic flexural, shear and bond-slip deformations and their interaction in plastic hinge regions of R/C members. 2nd COMPDYN Conference, Rhodes, Greece.

Mergos PE, Kappos AJ. 2012a. A gradual spread inelasticity model for R/C beam-columns accounting for flexure, shear and anchorage slip. Engineering Structures 44: 94-106.

Mergos PE, Kappos AJ. 2012b. A combined local damage index for seismic assessment of existing RC structures. Earthquake Engineering and Structural Dynamics. DOI: 10.1002/eqe.2247

Oesterle RG, Fiorato AE, Johal LS, Carpenter JE, Russell HG, Corley WG. 1976. Earthquake resistant structural walls - tests of isolated walls. Report to National Science Foundation. PCA Construction Technology Laboratories: Skokie.

Oesterle RG, Aristizabal-Ochoa JD, Shiu KN, Corley WG. 1984. Web crushing of RC structural walls. ACI Structural Journal 81: 231-241.

Orakcal K, Wallace JW. 2006. Flexural modeling of RC concrete walls - experimental verification. ACI Structural Journal 103: 196-206.

Ozcebe G, Saatcioglu M. 1989. Hysteretic shear model for reinforced concrete members. Journal of Structural Engineering 115: 132-148.

Park YJ, Reinhorn AM, Kunnath SK. 1987. IDARC: Inelastic damage analysis of reinforced concrete frame - shear wall structures. Report MCEER-87-0008, University at Buffalo, State Univ. of New York: New York.

Penelis GG, Kappos AJ. 1997. Earthquake-resistant concrete structures. E \& FN SPON (Chapman \& Hall): London.

Petrangeli M, Pinto P, Ciampi V. 1999. Fibre element for cyclic bending and shear or R/C structures. I: theory. Journal of Engineering Mechanics 125: 994-1001.

Priestley MJN, Calvi GM, Kowalsky MJ. 2007. Displacement-based Seismic Design of Structures. IUSS Press: Pavia, Italy.

Rabbat BG, Collins MP. 1978. A variable angle space truss model for structural concrete members subjected to complex loading. Douglas McHenry International Symposium on Concrete and Concrete Structures, SP-55, American Concrete Institute: Farmington Hills.

Reinhorn AM, Roh H, Sivaselvan M, Kunnath SK, Valles RE, Madan A, Li C, Lobo RF, Park YJ. 2009. IDARC2D Version 7.0: a program for the inelastic damage analysis of buildings. Report MCEER-09-0006, University at Buffalo, State Univ. of New York, New York.

Ricles JM, Yang YS, Priestley MJN. 1998. Modelling nonductile R/C columns for seismic analysis of bridges. Journal of Structural Engineering 124: 415-25.

Simonini S, Constantin R, Rutenberg A, Beyer K. 2012. Pushover analysis of multi-storey cantilever wall systems. In Proc. $15^{\text {th }}$ World Conf. on Earthq. Engineering: Lisboa, Portugal.

Sivaselvan MV, Reinhorn AM. 1999. Hysteretic model for cyclic behaviour of deteriorating inelastic structures. Report MCEER99-0018. University at Buffalo, State Univ. of New York: New York.

Soleimani D, Popov EP, Bertero VV. 1979. Nonlinear beam model for R/C frame analysis. Seventh Conference on Electronic Computation. St. Louis, Missouri. 
Spacone E, Filippou FC, Taucer FF. 1996. Fiber beam-column model for nonlinear analysis of R/C structures: formulation. Journal of Earthquake and Structural Dynamics 25: 711-725.

Takayanagi T, Derecho AT, Gorley WG. 1979. Analysis of inelastic shear deformation effects in reinforced concrete structural wall systems. In Proc. CSCE-ASCE-ACI-CEB International Symposium. University of Waterloo: Ontario, Canada.

Valenas JM, Bertero VV, Popov EP. 1979. Hysteretic behaviour of reinforced concrete structural walls. Report No. UBC/EERC79/20, University of California Berkeley, Berkeley, California.

Vecchio FJ, Collins MP. 1986. The modified compression field theory for reinforced concrete elements subjected to shear. ACI Structural Journal 83: 219-231.

Vecchio FJ, Lai D, Whim W, Ng J. 2001. Disturbed stress field model for reinforced concrete: validation. Journal of Structural Engineering 127: 350-358.

Vulcano A, Bertero VV, Colotti V. 1988. Analytical modelling of RC structural walls. In Proc. $9^{\text {th }}$ World Conf. Earth. Engineering: Tokyo-Kyoto, Japan; 41-46.

Wang TY, Bertero VV, Popov EP. 1975. Hysteretic behaviour of reinforced concrete framed walls. Report No. UBC/EERC-75/23, University of California Berkeley: Berkeley, California.

Wong P, Vecchio FJ. 2002. VecTor 2 and Formworks Manual. University of Toronto, Department of Civil Engineering: Canada.

\section{AUTHORS’ BIOGRAPHIES}

Panagiotis Mergos is a Postdoctoral Researcher at the École Polytechnique Fédérale de Lausanne in Lausanne, Switzerland. He received his $\mathrm{PhD}$ from the Aristotle University of Thessaloniki, Thessaloniki, Greece. His research interests include seismic design of reinforced concrete (RC) structures, assessment and retrofitting of RC structures with substandard detailing, distributed inelasticity finite element models and rocking isolation of bridge piers resting on spread foundations.

Katrin Beyer is an Assistant Professor of Earthquake Engineering at the École Polytechnique Fédérale de Lausanne in Lausanne, Switzerland. She received her PhD from the Rose School, Pavia, Italy. Her research interests include large-scale structural tests, the seismic behaviour of nonrectangular RC walls and unreinforced masonry structures, and the torsional response of asymmetric buildings when subjected to seismic excitation. 